\title{
Osteopenia in 37 Members of Seven Families: Analysis Based on a Model of Dominant Inheritance
}

\author{
Loretta D. Spotila, ${ }^{*}$ John Caminis, ${ }^{\dagger}$ Marcella Devoto, ${ }^{\neq}$ \\ Koichiro Shimoya, ${ }^{*}$ Larisa Sereda, ${ }^{*}$ Jürg Ott, ${ }^{*}$ \\ Michael P. Whyte, ${ }^{\S}$ Alan Tenenhouse, ${ }^{+}$ \\ and Darwin J. Prockop* \\ *Department of Biochemistry and Molecular Biology, \\ Jefferson Medical College, Thomas Jefferson University, \\ Philadelphia, Pennsylvania, U.S.A. \\ ${ }^{+}$The Montreal General Hospital, Montreal, Quebec, Canada \\ ${ }^{\ddagger}$ Department of Psychiatry, Columbia University, New York, \\ New York, U.S.A. \\ ${ }^{\S}$ Metabolic Research Unit, Shriners Hospital for Crippled Children and \\ Division of Bone and Mineral Diseases, Washington University School \\ of Medicine, St. Louis, Missouri, U.S.A.
}

\begin{abstract}
Background: The genetic factors involved in determining bone mineral density (BMD) have not been fully elucidated. We have begun genetic linkage analysis of seven families in which many members are osteopenic, in order to identify chromosomal loci that are potentially involved in determining BMD.

Materials and Methods: Spine BMD was measured in 143 members of seven kindred with familial osteopenia. The absolute BMD values for the spine (L2-L4) were converted to the age-, gender-, and weight-adjusted $Z$ scores, and this corrected value was used as the quantitative trait on which to base subsequent genetic analyses. Simulations of linkage were performed in order to determine the information content of the pedigree set, and actual linkage analysis was conducted using polymor-
\end{abstract}

phic markers either within or near three candidate loci: COLlA1, COLlA2, and vitamin D receptor (VDR).

Results: The distribution of the corrected $Z$ scores was bimodal $(p=0.001)$ suggesting a monogenic mode of inheritance of the low BMD trait. Simulation of linkage analysis suggested that the family data set was sufficient to detect linkage under a single major gene model. Actual linkage analysis did not support linkage to the three candidate loci. In addition, the VDR genotype was not statistically associated with low bone density at the spine. Conclusions: Loci other than COLlAl, COLlA2 and VDR are very likely responsible for the low BMD trait observed in these families. These families are suitable for a genome-wide screen using microsatellite repeats in order to identify the loci that are involved in osteopenia.

\section{INTRODUCTION}

Bone mineral density (BMD) measurements are a quantitative assessment of the mineral content of the skeleton. The BMD of the lumbar verte-

Address correspondence and reprint requests to: Loretta D. Spotila, Department of Biochemistry and Molecular Biology, Jefferson Medical College, Thomas Jefferson University, 233 South Tenth Street, Philadelphia, PA 19107, U.S.A. brae and the hip (femoral neck, trochanter, and Ward's triangle) is directly related to bone strength of the spine and hip, respectively $(1,2)$. Risk of fracture increases as BMD decreases (3), but fractures may be absent in some individuals with very low bone density. Conversely, fractures may be present in individuals with normal bone density. Two of the major determinants of BMD are the peak BMD attained during growth 
(4-6), and the rate at which mineral is lost from the skeleton during aging $(7,8)$. Although many factors can influence these two determinants of $B M D$, evidence from studies of twins (9-12), mother/daughter pairs $(13,14)$, and parent/offspring pairs (15) suggests that genetic factors play a major role (16). Studies of heritable disorders such as osteogenesis imperfecta (OI) $(17,18)$ and vitamin D-dependent rickets type II (19) demonstrate that mutations in the type I procollagen genes (COLlAl and COLlA2) and the vitamin $\mathrm{D}$ receptor gene (VDR) cause abnormal bone. However, collagen gene defects account for only a small fraction of familial osteoporosis (20), and despite the association between VDR genotype and low bone density observed in some populations $(21,22)$, no mutation has been found that causes low BMD. Since fractures caused by low BMD are a major source of morbidity and health care costs in the elderly, it is important to define other genetic factors that might be involved in controlling BMD.

One approach to identifying genetic factors involved in complex traits has been genetic linkage analysis. Linkage analysis requires that an identifiable status or trait be present in multiple family members and that the structure of the families be informative. To date, low BMD and/or osteoporosis have not been assessed in families that were of suitable size and structure to provide a basis for genetic linkage analysis. Thus, we have estimated the potential of the seven families described here to serve as such a basis for linkage analysis. In addition, we have analyzed linkage to three candidate genes: COL1A1, COL1A2, and VDR.

\section{MATERIAL AND METHODS}

\section{Clinical}

Family members of seven kindred were evaluated at the Metabolic Bone Clinic, Montreal General Hospital Metabolic Bone Clinic (Families 01, 02, 03, 04, 06, and 07), or the Metabolic Research Unit, Shriners Hospital for Crippled Children, St. Louis (Family 05).

Spinal BMD was measured in all participating family members over the age of 20 by dual energy X-ray absorptiometry (DEXA) using either a Lunar DPX (Lunar, Madison, WI, U.S.A.; Families 01, 02, 03, 04, 06, and 07) or a Hologic QDR-2000 (Hologic, Waltham, MA, U.S.A.; Family 05). In general, values of BMD obtained by the Hologic instrument have been shown to be about $6-12 \%$ lower than those obtained using the Lunar instrument (23). Eight individuals from three families $(02,04$, and 06) had BMD measurements performed at other clinics because it was not possible for them to travel to Montreal. However, the instrument used in these cases was also a Lunar DPX. The spinal BMD measurements, in $\mathrm{g} / \mathrm{cm}^{2}$, were converted to $Z$ scores based on the age-, gender-, and weight-matched normal population data base provided by the manufacturer of each densitometer. All individuals were questioned with regard to known causes of osteopenia, including hormonal deficiencies or therapy, poor nutritional status, alcohol consumption, smoking, and lack of exercise. Scleral hue and childhood fracture history were determined for the proband of each family. All participants gave their informed consent, and the research protocols were approved by the Institutional Review Boards for The Montreal General Hospital, Washington University School of Medicine, and Thomas Jefferson Medical College.

\section{Statistical Methods}

The age-, gender-, and weight-adjusted BMD $Z$ scores for the spine were plotted, and a likelihood ratio test using first the NOCOM program (24) and then the ILINK (25) program was applied to determine whether a single distribution or a mixture of two distributions best described the BMD data. NOCOM does not consider familial relationships; hence ILINK, which does consider relationships, was used to refine the analysis. Means and standard deviations for the two components of the distribution were estimated using the ILINK program. Multiple regression was performed using the FASTAT statistics software package (Systat, Inc., Evanston, IL, U.S.A.) on the spinal BMD with age, height, weight, and VDR genotype as independent variables.

\section{Simulation Study}

The corrected spinal BMD $Z$ score was chosen as the phenotypic variable on which to evaluate linkage in the simulation studies because the high trabecular bone content of the vertebrae renders this site more sensitive to change (26) and because determination of spinal BMD is technically the most reproducible (27). Genotypes were simulated using the SLINK program $(28,29)$ for a polymorphic marker that was lo- 
cated at each of three recombination distances $(\theta)$ from the hypothetical BMD locus. The three values for $\theta$ were 0.01 , representing a $1 \%$ recombination rate; 0.05 , representing a $5 \%$ recombination rate; and 0.50 , representing a $50 \%$ recombination rate and therefore no linkage between the marker locus and the hypothetical single major gene locus responsible for the $\mathrm{BMD}$ trait. The polymorphic marker locus was assumed to have four alleles of equal frequency $(0.25)$ corresponding to a heterozygosity of $75 \%$, and the hypothetical trait allele was assigned a frequency of 0.01. Expected and maximum lod scores at the different values of the recombination fraction, and the probability that the maximum lod score will exceed a given value, were evaluated from 100 replicates for $\theta=0.01$ and $\theta=0.05$ and 1000 replicates for $\theta=0.50$ using the analysis program MSIM $(28,29)$.

\section{Molecular Analysis}

Blood was collected in EDTA-coated tubes and genomic DNA was isolated according to the manufacturer's protocol for an automated instrument (Genepure 341; Applied Biosystems Inc., Foster City, CA, U.S.A.). The polymerase chain reaction (PCR) was used to determine the allelic status of all individuals for the following polymorphic loci: COL1A2 intron 1 (30), COL1A2 intron 12 (31), D7S558 (32), HOX2B (33), Dl7S806 (34), DI7S798 (34), and the VNTR in the $3^{\prime}$-untranslated region of $\operatorname{COL} 2 A 1(35,36)$. PCRs were carried out using one oligonucleotide with a $5^{\prime}{ }^{32} \mathrm{P}$-label and the other oligonucleotide unlabeled. Products were analyzed on a $6 \%$ sequencing gel by autoradiography.

The VDR genotype was determined as follows. Two oligonucleotide primers (21) were used to amplify a portion of the VDR gene by performing $30-40$ cycles of $94.5^{\circ} \mathrm{C}$ denaturation for $30 \mathrm{sec}, 60^{\circ} \mathrm{C}$ annealing for $30 \mathrm{sec}$, and $72^{\circ} \mathrm{C}$ extension for $1 \mathrm{~min}$ in a thermocycler model 9600 (Perkin Elmer Cetus, Norwalk, CT, U.S.A.). PCR products of approximately $870 \mathrm{bp}$ were checked on an agarose gel and approximately $100 \mathrm{ng}$ was used in a restriction digest with BsmI at $65^{\circ} \mathrm{C}$ for $1 \mathrm{hr}$. Presence of the polymorphic $B s m I$ site was detected as two subfragments of approximately 690 and 180 bp.

\section{Linkage Analysis}

Two-point lod scores were calculated at recombination distances $(\theta)$ of $0,0.01,0.05,0.10,0.20$, and 0.30 using the program MLINK (25). For each marker the number of alleles and allele frequencies were based on those observed in our family population. The putative disease allele was considered to have a population frequency of 0.01 .

\section{RESULTS \\ Defining the Test Trait}

The seven families in this study were chosen based on the size and availability of the family as well as the clinicians' foreknowledge of multiple members with low bone density. The individual who was evaluated first in each family was designated as the proband (Fig. 1, arrows). The ethnic backgrounds were as follows: French Canadian (Families 01 and 07), Greek (Families 02 and 04), Jewish (Families 03 and 06), and unknown (Family 05). There was no evidence of osteogenesis imperfecta in the probands as indicated by sclerae that were white, stature that was normal, and absence of a family history of childhood fractures and dental abnormalities. The probands had a diagnosis of osteoporosis on the basis of spinal BMD value $>2.0$ SD below the young-adult mean, or radiographic evidence of osteopenia together with the presence of pathological fractures and unremarkable biochemical studies. However, for the purpose of this genetic study we did not use the physician's diagnosis of presence or absence of osteoporosis to define status in family members. Rather, we used the age-, gender-, and weight-adjusted $Z$ score for spinal BMD as the trait on which to base all analysis.

For purposes of illustration, in Fig. 1, the adjusted spinal $Z$ score is indicated by the extent to which a symbol is filled, an unfilled symbol indicating $Z>-1.00$ and a completely filled symbol indicating $Z<-2.5$. Of the 143 individuals evaluated, 37 had corrected spinal $Z$ scores that were $<-2.00$, indicating osteopenia. Five individuals were not included in the statistical analysis because their spines had radiographic evidence of sclerotic changes that compromised use of the spinal $Z$ score: III-7, III-9, and III- 11 in Family 02; I-1 in Family 03; II-5 in Family 04. One individual, II-5 (Family 01) was excluded because of medication (glucocorticoids) and lifestyle (smoker, $>2$ packs of cigarettes/day). Her identical twin (II-5A) had higher BMD, was not a smoker and was not taking steroids. Another 
Family 01

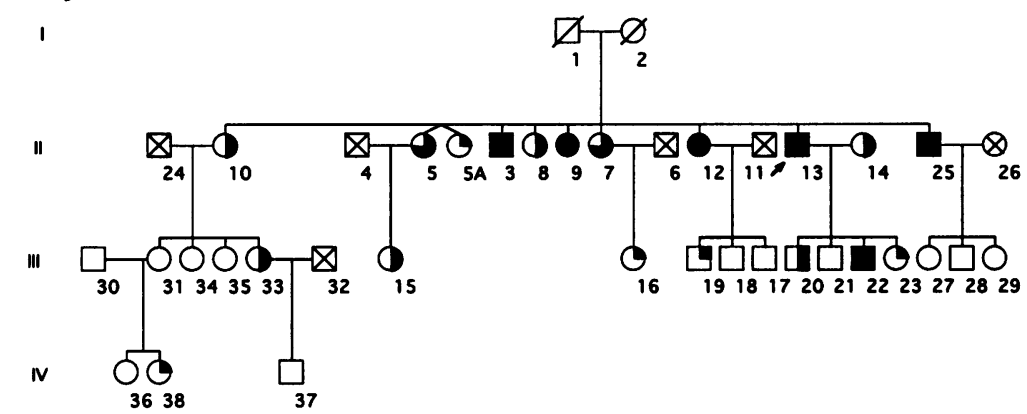

Family 02

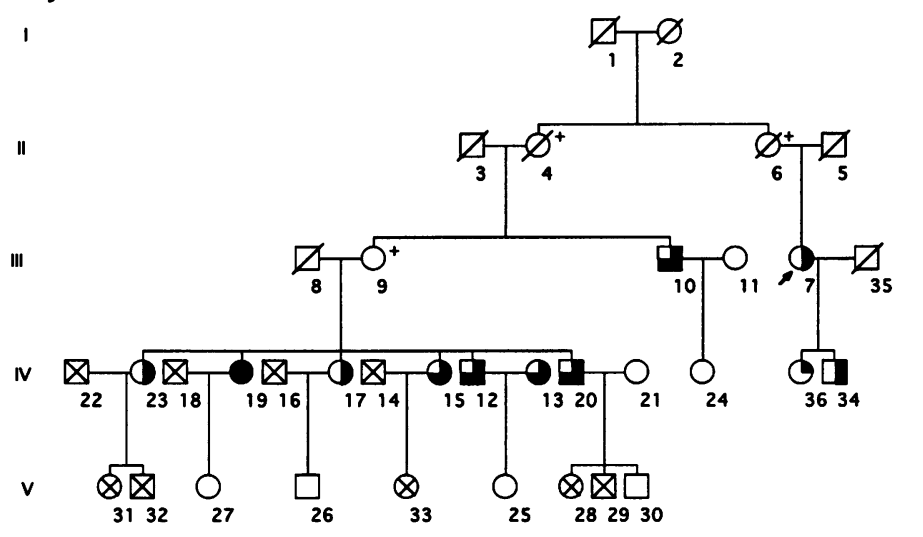

Family 03

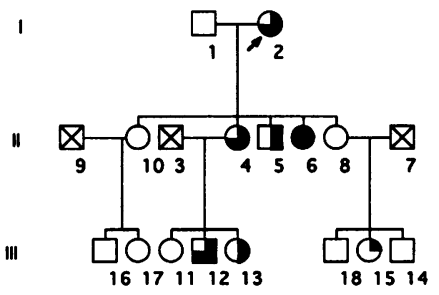

Family 04

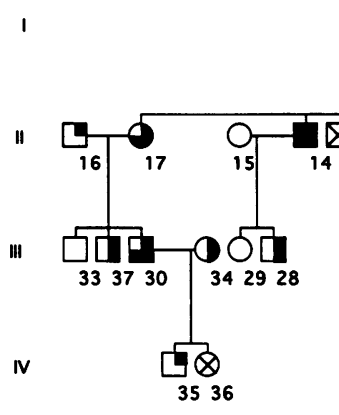

Family 06

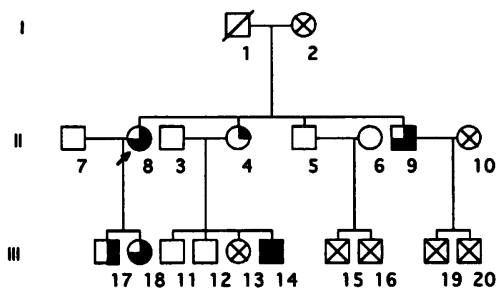

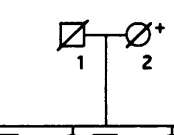

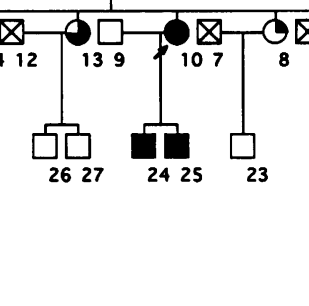

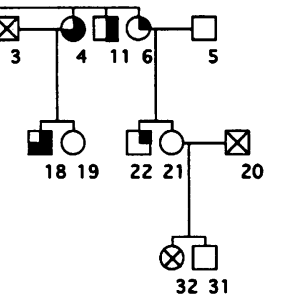

Family 05

Family 07

I
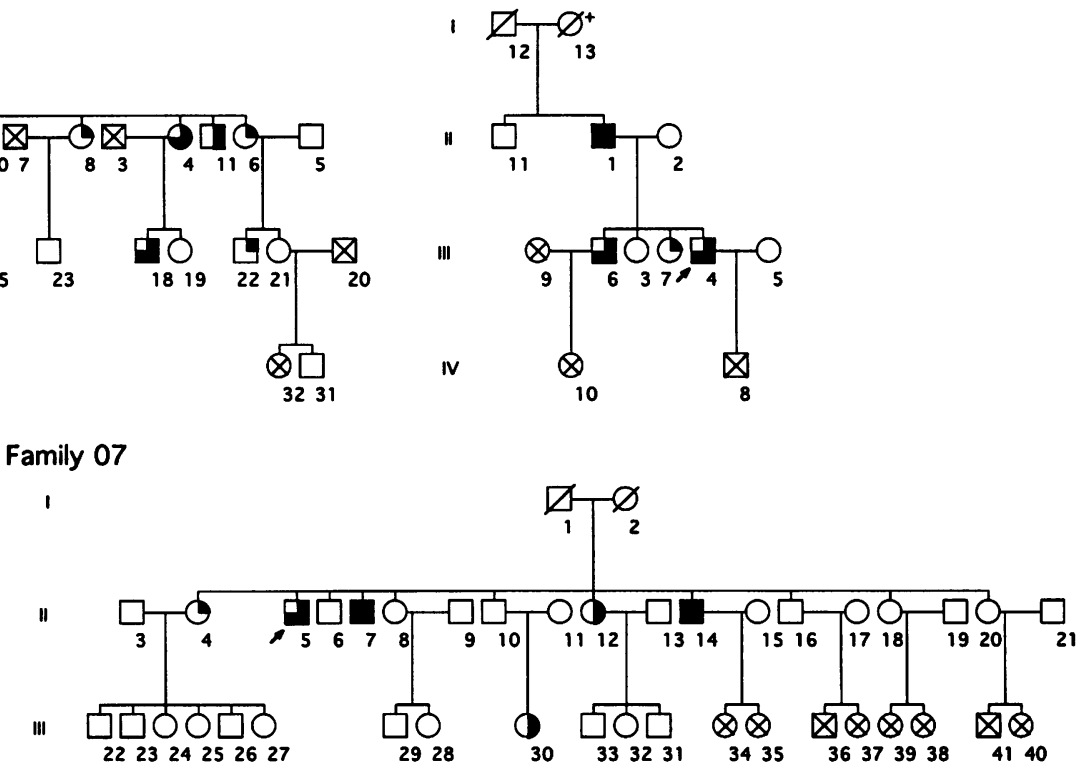

FIG. 1. Pedigrees of the seven families

Filled symbols indicate spinal BMD $Z$ score $<-2.50$; three/quarter-filled symbols indicate $Z$ score between -2.50 and -2.00; half-filled symbols indicate $Z$ score between -2.00 and -1.50 ; one/quarter-filled symbols indicate $Z$ scores between -1.50 and -1.00 ; unfilled symbols indicate $Z$ score $>-1.00$. Symbols with $X$ indicate that the individual was not tested; symbols with ${ }^{+}$indicate anecdotal evidence of osteoporosis or radiographic evidence of osteopenia. Arrows indicate the proband in each family. Family 01 has one set of monozygotic twins. 


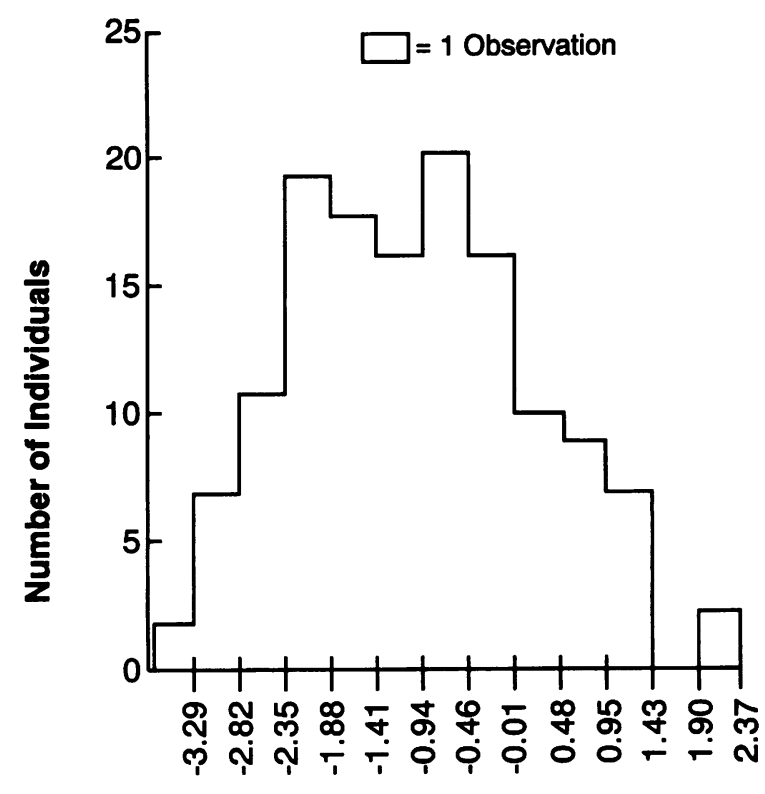

Z Score for Spinal BMD

FIG. 2. Distribution of age-, weight-, and gender-corrected spinal BMD $Z$ scores for 136 individuals

The distribution was analyzed using the ILINK likelihood ratio test (25), which suggested that the bimodal character was significant $(p=0.001)$.

individual, III-30 (Family 07) was excluded from the analysis because she had undergone a renal transplant and was receiving immune suppressants. There were no significant medical or lifestyle indications to exclude any other individuals from analysis. Although several subjects were being treated with either estrogen or bisphosphonates prior to recruitment for the study, a pretreatment baseline BMD was available. Of the 37 individuals with $Z$ scores $<-2.00,24$ (64.9\%) had had at least one fracture. Eighteen individuals had corrected spinal $Z$ scores between -1.5 and -2.0 , and 8 of them $(44.4 \%)$ had experienced a fracture. Of the remaining 81 individuals with spinal $Z$ scores $>-1.5,21(25.9 \%)$ had fractured at least once.

Commingling analysis (25), performed on the distribution of adjusted spinal BMD $Z$ scores after exclusion of the probands, demonstrated that a mixture of two components provided a better fit to the $Z$ score distribution than a single component with a unimodal distribution (Fig. 2). The $\chi^{2}$-statistic of $13.9(2 \mathrm{df})$ has an associated $p$ value of 0.001 (37), and, therefore, supported the hypothesis of two components. This result satisfied a necessary condition for assuming the presence of genetic factors that determine BMD and suggested a monogenic mode of inheritance. The individuals in the two groups defined by the bimodal distribution could be taken to represent distinct genotypic classes at an underlying genetic locus and provide the basis for defining the test trait. Estimated by the ILINK program (25), the means of the two distributions were -0.004 and -1.656 , with a common SD of 0.917 .

\section{Simulation of Linkage}

Based on the outcome of the commingling analysis of the spinal $Z$-score distribution, we assumed that the transmission of BMD followed an autosomal dominant mode of inheritance, with the allele predisposing to low BMD having a frequency of 0.01 . The mean $Z$ score of -0.004 was used for individuals who were homozygous for the normal BMD allele, and the mean $Z$ score of -1.656 was used for heterozygotes or homozygotes for the low BMD allele. Simulation analysis was carried out as described in Materials and Methods. The analysis was performed on each family individually, as well as for all seven families combined, since it is not known if the same locus is involved in determining BMD in more than one family. The results are presented as the average and maximum lod score for different values of the recombination fraction (Table 1), and as the probability that the maximum lod score exceeds a given constant (Table 2 ). The average lod scores are indicative of the information content of these pedigrees for linkage analysis, and the probability that the maximum lod score exceeds a given constant is a direct estimate of the power of the analysis. The analyses indicated that there was a $52 \%$ probability of obtaining a lod score $>+3.00$ and a $73 \%$ probability of obtaining lod score $>+2.00$ for a true value of $\theta=0.05$, if the initial assumptions were correct. For a true value of $\theta=0.01$, the probability of obtaining a lod score $>+3.00$ was $74 \%$ and of obtaining a lod score $>+2.00$ was $89 \%$. Families 02,04 , and 07 are each of suitable structure and size to yield lod scores of $>+2.00$.

The probability of obtaining a false positive result is represented by the percentage of maximum lod-score values $>3$ when $\theta=0.50$. In our study this was found to be 0 . 
TABLE 1. Average and maximum lod score at given values for $\theta$ as predicted by simulation analyses

\begin{tabular}{ccc}
\hline \multicolumn{2}{l}{ Family } & \\
\hline \multicolumn{2}{l}{ A. For True $\theta=0.01$} & $\theta=0.05$ \\
& $\theta=0.01$ & $0.39(1.71)$ \\
01 & $0.41(1.84)^{a}$ & $0.59(2.23)$ \\
02 & $0.60(2.45)$ & $0.39(1.44)$ \\
03 & $0.40(1.55)$ & $0.94(2.69)$ \\
04 & $0.98(2.84)$ & $0.18(0.54)$ \\
05 & $0.19(0.60)$ & $0.45(1.33)$ \\
06 & $0.46(1.46)$ & $0.97(2.62)$ \\
07 & $1.01(2.84)$ & $3.94(7.42)$ \\
Study & $4.07(8.11)$ & \\
B. For True $\theta=0.05$ & $0.26(1.56)$ \\
01 & $0.24(1.75)$ & $0.39(2.16)$ \\
02 & $0.36(2.38)$ & $0.29(1.43)$ \\
03 & $0.27(1.55)$ & $0.78(2.69)$ \\
04 & $0.77(2.84)$ & $0.12(0.54)$ \\
05 & $0.12(0.60)$ & $0.36(1.33)$ \\
06 & $0.35(1.46)$ & $0.73(2.62)$ \\
07 & $0.70(2.85)$ & $2.92(6.74)$ \\
Study & $2.81(7.20)$ & \\
& &
\end{tabular}

${ }^{a}$ Maximum lod score in parentheses.

\section{Molecular and Linkage Analysis}

Three genes were of immediate interest for testing linkage to the low bone density trait. COLlAl and COLlA2 encode the two chains of type I procollagen, the principal protein in bone matrix, and have been shown to have causative mutations in osteogenesis imperfecta $(17,18)$. The vitamin $\mathrm{D}$ receptor (VDR) gene has been recently implicated by the association of VDR genotype with bone density (21). Therefore, we tested for linkage to these genes by analyzing polymorphic markers either within or near the gene of interest. There are several diallelic polymorphisms within the COLlAl gene, but none of these were informative in these families. Thus, three multiallelic markers that lie in the same interval of chromosome 17 as the COLlAl gene were tested. The genetic map of chromosome 17 places the COLlAl gene in the same $13.9 \mathrm{cM}$ interval as D17S798, D17S806, and HOX2B (32). The lod scores calculated for each family individually as well as all together (Table 3 below) did
TABLE 2. Results of simulation analysis

\begin{tabular}{|c|c|c|c|c|}
\hline $\begin{array}{l}\text { Lod } \\
\text { Score }\end{array}$ & Family & $\begin{array}{c}\text { True } \\
\theta=0.01\end{array}$ & $\begin{array}{c}\text { True } \\
\theta=0.05\end{array}$ & $\begin{array}{c}\text { True } \\
\theta=0.50\end{array}$ \\
\hline \multirow[t]{8}{*}{2.00} & 01 & 0 & 0 & 0 \\
\hline & 02 & 5 & 3 & 0 \\
\hline & 03 & 0 & 0 & 0 \\
\hline & 04 & 17 & 10 & 0 \\
\hline & 05 & 0 & 0 & 0 \\
\hline & 06 & 0 & 0 & 0 \\
\hline & 07 & 15 & 12 & 1 \\
\hline & Study & 89 & 73 & 2 \\
\hline \multirow[t]{8}{*}{3.00} & 01 & 0 & 0 & 0 \\
\hline & 02 & 0 & 0 & 0 \\
\hline & 03 & 0 & 0 & 0 \\
\hline & 04 & 0 & 0 & 0 \\
\hline & 05 & 0 & 0 & 0 \\
\hline & 06 & 0 & 0 & 0 \\
\hline & 07 & 0 & 0 & 0 \\
\hline & Study & 74 & 52 & 0 \\
\hline
\end{tabular}

Number of (interpolated) maximum lod scores greater than a given critical value obtained from 100 replicates at $\theta=$ 0.01 and $\theta=0.05$, and 1000 replicates at $\theta=0.50$.

not support linkage of this chromosomal interval to the low spinal BMD trait. When the lod scores are summed over all families, linkage was excluded to more than $5 \mathrm{cM}$ on either side of markers HOX2B and D17S798. However, each family, taken individually, did not produce statistically significant lod scores for exclusion.

Unlike COLlAl, there are several multiallelic markers within the COL1A2 gene. Summed over all families, COL1 A2 could be excluded (Table 3) with a lod score of $<-3.00$ for $\theta<0.01$. Taken individually, Family 03 suggested linkage (lod $=0.85$, intron 12). To test for a mutation in COL1A2 in Family 03, cDNA was prepared from skin fibroblasts of individual II-4 and sequenced as in Spotila et al. (20). No mutation was found, and the presence of a polymorphism indicated that both alleles were expressed. From these results we conclude that COL1Al and COL1A2 are not linked to the low spinal BMD trait in these families with the possible exception of COL1A2 in Family 03.

The procollagen II (COL2Al) gene is located at 0 recombination distance from the VDR locus (38). A VNTR in the $3^{\prime}$-untranslated region of 
COL2Al $(35,36)$ was used as a marker for linkage to VDR. Results are shown in Table 3. There is no evidence for linkage to VDR with the possible exception of Family 06 (lod $=0.79)$. Overall, linkage was excluded with a total lod score of -3.40 at $\theta=0$. Family 04 was assayed for several other markers in the 12q12-q14 interval of chromosome 12 (D12S61, D12S62, D12S87), and the lod scores were $<-2.00$ (Spotila, unpublished). Thus, with the possible exception of Family 06, we conclude that there is no evidence for linkage of the low BMD trait to the VDR locus.

Recently, the VDR genotype was reported to be associated with BMD and to account for up to $75 \%$ of the genetic effect on spinal bone density in a randomly selected Australian population as well as a population of Australian twins (21) although Hustmyer et al. (22) failed to observe a similar association in a group of American twins. The VDR genotype associated with low bone density in the Australian group was identified by the absence of a polymorphic $B s m I$ restriction endonuclease site (designated $\mathrm{BB}$ ) (21). Therefore, we determined the VDR genotype (i.e., BB, $\mathrm{Bb}, \mathrm{bb}$ ) in 114 individuals from the seven pedigrees as described in Materials and Methods. Multiple regression was then performed on the data from men and women individually using spinal BMD as the dependent variable and age, height, weight, and VDR genotype as the independent variables (Table 4 ). The coefficients for VDR genotype were not significant in the regression equations, and the VDR genotype accounted for only $0.7 \%$ of the variance in spinal BMD in men and $1.2 \%$ in women (Table 4 ). The mean $( \pm \mathrm{SD})$ spinal $Z$ score for each genotype was as follows: $-0.919( \pm 1.286)$ for genotype $\mathrm{BB}$, $-0.931( \pm 1.262)$ for genotype $\mathrm{Bb}$, and -1.221 $( \pm 1.448)$ for genotype bb. Although there is a trend toward lower $Z$ score with the bb homozygote, these differences were not statistically significant.

\section{DISCUSSION}

Genetic linkage analysis is a powerful tool that has contributed greatly to the identification of genes involved in many single gene disorders such as cystic fibrosis, neurofibromatosis and fragile X-linked mental retardation (39). More recently, linkage analysis has been used to identify genetic loci involved in diseases that appear to have both complex genetic causes and sub- stantial environmental influences. Examples are familial breast cancer (40), colon cancer (41), diabetes mellitus (42), and hypertension (43). The success of the search for disease-causing genes requires suitably large families in which the status of individuals can be ascertained with reasonable confidence. In this study, we have used the age-, weight-, and gender-adjusted spinal BMD $Z$ score as the quantitative phenotypic trait on which to base a genetic analysis. Because this is a quantitative variable, it is more informative than dichotomization into affected and unaffected clinical status. Since each individual has a BMD value, each individual is potentially informative. In this study of 143 family members, 37 individuals were identified who had spinal BMD values more than 2 SD below the age-, weight-, and gender-matched population and an additional 18 were 1.5-2.0 SD below. More than $50 \%$ of these individuals had a history of one fracture, but many were asymptomatic.

In the seven families described here, genetic factors appear to be important in causing low BMD for several reasons. Firstly, individuals in multiple generations have low BMD, suggesting that factors in addition to environment are involved. Secondly, transmission appears to be Mendelian, from affected parent to child, suggesting a dominant mode of inheritance. The observation of a bimodal distribution of adjusted spinal $Z$ scores is also consistent, although it does not prove a dominant mode of inheritance. Thirdly, the number of men and women affected is approximately equal, thus indicating that estrogenic/androgenic-related factors and X-linked inheritance do not fully account for the observations. Finally, some relatively young individuals were found to have adjusted $Z$ scores of $<-2.00$, consistent with there being a defect in the attainment of peak bone mass. Overall, however, there is an age bias toward lower adjusted BMD $Z$ scores in older individuals. This may indicate that the rate of bone loss in these families is also affected by genetic factors.

The statistically significant outcome of the commingling analysis on the age-, gender-, and weight-adjusted spinal BMD $Z$ scores $(p=0.001)$ supports a monogenic inheritance mode of the low spinal bone density trait in these families.

The suitability of the seven families for linkage analysis was determined by computer simulation. This type of analysis is useful for determining the probability of detecting linkage given a particular set of data prior to carrying out molecular analyses. In the past, one limitation to 
TABLE 3. Lod scores for markers at or near the COL1A1, COL1A2, and VDR loci

\begin{tabular}{|c|c|c|c|c|c|c|}
\hline \multirow[b]{2}{*}{ Marker/Family } & \multicolumn{6}{|c|}{ Lod score at $\theta=$} \\
\hline & 0.0 & 0.01 & 0.05 & 0.1 & 0.2 & 0.3 \\
\hline \multicolumn{7}{|l|}{ D17S798 } \\
\hline 1 & -0.97 & -0.91 & -0.69 & -0.48 & -0.20 & -0.07 \\
\hline 2 & -0.29 & -0.29 & -0.29 & -0.25 & -0.13 & -0.05 \\
\hline 3 & \multicolumn{2}{|c|}{ Not determined } & & & & \\
\hline 4 & -0.72 & -0.66 & -0.47 & -0.30 & -0.10 & -0.03 \\
\hline 5 & -0.62 & -0.56 & -0.39 & -0.26 & -0.12 & -0.05 \\
\hline 6 & -1.05 & -1.00 & -0.81 & -0.61 & -0.30 & -0.12 \\
\hline 7 & -0.25 & -0.23 & -0.15 & -0.07 & 0.02 & 0.03 \\
\hline Total & -3.90 & -3.65 & -2.80 & -1.96 & -0.84 & -0.29 \\
\hline \multicolumn{7}{|l|}{ HOX2B } \\
\hline 1 & -0.91 & -0.88 & -0.75 & -0.59 & -0.34 & -0.15 \\
\hline 2 & 0.17 & 0.22 & 0.35 & 0.43 & 0.42 & 0.28 \\
\hline 3 & -2.01 & -1.85 & -1.39 & -1.02 & -0.55 & -0.26 \\
\hline 4 & -0.02 & 0.00 & 0.07 & 0.10 & 0.10 & 0.05 \\
\hline 5 & -0.70 & -0.64 & -0.45 & -0.31 & -0.14 & -0.07 \\
\hline 6 & -0.48 & -0.44 & -0.34 & -0.25 & -0.14 & -0.07 \\
\hline 7 & -0.34 & -0.31 & -0.16 & 0.01 & 0.17 & 0.16 \\
\hline Total & -4.28 & -3.89 & -2.67 & -1.63 & -0.48 & -0.05 \\
\hline \multicolumn{7}{|l|}{ D17S806 } \\
\hline 1 & -1.50 & -1.38 & -1.07 & -0.80 & -0.42 & -0.18 \\
\hline 2 & -0.67 & -0.63 & -0.47 & -0.30 & -0.09 & -0.02 \\
\hline 3 & \multicolumn{2}{|c|}{ Not determined } & & & & \\
\hline 4 & -1.12 & -1.01 & -0.69 & -0.41 & -0.12 & -0.03 \\
\hline 5 & -0.02 & -0.02 & -0.02 & -0.01 & -0.01 & -0.00 \\
\hline 6 & 0.13 & 0.18 & 0.28 & 0.31 & 0.26 & 0.14 \\
\hline 7 & 0.12 & 0.11 & 0.08 & 0.06 & 0.06 & 0.07 \\
\hline Total & -3.06 & -2.76 & -1.89 & -1.15 & -0.32 & -0.01 \\
\hline \multicolumn{7}{|l|}{ Intron $1 \mathrm{COL} 1 \mathrm{~A} 2$} \\
\hline 1 & -0.38 & -0.36 & -0.29 & -0.21 & -0.08 & -0.01 \\
\hline 2 & -0.49 & -0.47 & -0.39 & -0.29 & -0.16 & -0.07 \\
\hline 3 & -0.01 & -0.01 & -0.01 & -0.01 & -0.01 & -0.00 \\
\hline 4 & -0.89 & -0.84 & -0.69 & -0.52 & -0.27 & -0.10 \\
\hline 5 & -0.57 & -0.51 & -0.35 & -0.24 & -0.11 & -0.04 \\
\hline 6 & -0.99 & -0.91 & -0.68 & -0.47 & -0.23 & -0.09 \\
\hline 7 & -0.66 & -0.64 & -0.58 & -0.49 & -0.28 & -0.12 \\
\hline Total & -3.99 & -3.76 & -2.99 & -2.24 & -1.13 & -0.44 \\
\hline \multicolumn{7}{|l|}{ Intron 12 COL $1 \mathrm{~A} 2$} \\
\hline 1 & -0.21 & -0.21 & -0.18 & -0.15 & -0.09 & -0.04 \\
\hline 2 & 0.01 & 0.01 & 0.02 & 0.02 & 0.03 & 0.04 \\
\hline 3 & 0.85 & 0.83 & 0.75 & 0.65 & 0.46 & 0.28 \\
\hline 4 & -0.88 & -0.84 & -0.68 & -0.53 & -0.28 & -0.12 \\
\hline 5 & -0.61 & -0.55 & -0.39 & -0.26 & -0.12 & -0.05 \\
\hline 6 & -0.87 & -0.80 & -0.59 & -0.42 & -0.21 & -0.08 \\
\hline 7 & -1.55 & -1.54 & -1.45 & -1.19 & -0.63 & -0.25 \\
\hline Total & -3.26 & -3.09 & -2.52 & -1.86 & -0.83 & -0.24 \\
\hline
\end{tabular}


TABLE 3. continued

\begin{tabular}{|c|c|c|c|c|c|c|}
\hline \multirow[b]{2}{*}{ Marker/Family } & \multicolumn{6}{|c|}{ Lod score at $\theta=$} \\
\hline & 0.0 & 0.01 & 0.05 & 0.1 & 0.2 & 0.3 \\
\hline \multicolumn{7}{|l|}{ D7S558 } \\
\hline 1 & \multicolumn{2}{|c|}{ Not determined } & & & & \\
\hline 2 & 0.18 & 0.19 & 0.19 & 0.19 & 0.14 & 0.07 \\
\hline 3 & 0.23 & 0.23 & 0.21 & 0.19 & 0.19 & 0.14 \\
\hline 4 & -1.17 & -1.10 & -0.88 & -0.66 & -0.35 & -0.15 \\
\hline 5 & \multicolumn{2}{|c|}{ Not determined } & & & & \\
\hline 6 & \multicolumn{2}{|c|}{ Not determined } & & & & \\
\hline 7 & \multicolumn{2}{|c|}{ Not determined } & & & & \\
\hline Total & -0.76 & -0.69 & -0.47 & -0.28 & -0.08 & -0.01 \\
\hline \multicolumn{7}{|l|}{ COL2Al } \\
\hline 1 & -0.15 & -0.14 & -0.09 & -0.05 & -0.00 & -0.03 \\
\hline 2 & -0.45 & -0.44 & -0.41 & -0.34 & -0.20 & -0.08 \\
\hline 3 & -1.35 & -1.28 & -1.05 & -0.81 & -0.46 & -0.24 \\
\hline 4 & \multicolumn{2}{|c|}{ Not determined } & & & & \\
\hline 5 & -0.73 & -0.68 & -0.50 & -0.35 & -0.17 & -0.07 \\
\hline 6 & 0.79 & 0.78 & 0.72 & 0.63 & 0.43 & 0.22 \\
\hline 7 & -1.52 & -1.47 & -1.22 & -0.92 & -0.49 & -0.22 \\
\hline Total & -3.40 & -3.23 & -2.54 & -1.83 & -0.88 & -0.36 \\
\hline
\end{tabular}

linkage studies was the lack of a sufficiently large number of informative polymorphic genetic markers. More recently, with the development of large sets of mapped genetic markers $(32,39,44)$ the main limitation has become the availability of suitable pedigrees. Here, the expected lod scores were computed for each family as well as for all families combined, because it is not yet known if the same loci will be involved in all seven families. Three of the families $(02,04$, and 07) are each large enough and of suitable composition to give lod scores approaching +3.00 . When all families are considered, the probability of obtaining a significant lod score

TABLE 4. Multiple regression analysis of uncorrected values for spinal BMD (L2-L4) in males and females from the seven families who were tested for VDR genotype

\begin{tabular}{|c|c|c|c|c|c|c|}
\hline \multirow[b]{2}{*}{ Variable } & \multicolumn{3}{|c|}{ Males $(n=56)$} & \multicolumn{3}{|c|}{ Females $(n=58)$} \\
\hline & Coefficient & & $\boldsymbol{p}$ & Coefficient & & $p$ \\
\hline Constant & 0.121 & & 0.828 & 0.540 & & 0.148 \\
\hline Age (years) & 0.001 & & 0.767 & -0.007 & & 0.000 \\
\hline Height $(\mathrm{cm})$ & 0.004 & & 0.236 & 0.003 & & 0.129 \\
\hline Weight (kg) & 0.004 & & 0.023 & 0.004 & & 0.002 \\
\hline VDR & -0.021 & & 0.508 & -0.029 & & 0.266 \\
\hline $\mathrm{R}^{2}$ & \multicolumn{3}{|c|}{0.189} & \multicolumn{3}{|c|}{0.517} \\
\hline $\begin{array}{l}\mathrm{R}^{2} \text { if } \mathrm{VDR} \text { is excluded } \\
\text { from regression }\end{array}$ & \multicolumn{3}{|c|}{0.182} & \multicolumn{3}{|c|}{0.505} \\
\hline
\end{tabular}


greater than +3.00 was $52 \%$ at a true recombination distance of $5 \mathrm{cM}$ and $74 \%$ at a true recombination distance of $1 \mathrm{cM}$.

Before beginning a genome-wide screen for linkage, we tested whether the low BMD trait was linked to COL1A1, COL1A2, or VDR under the assumed monogenic mode of inheritance. The results of assaying several polymorphic markers either within or near these loci have permitted the exclusion of these loci in some families. Moreover, there is no evidence for linkage to these loci. The one slightly positive lod score of +0.81 for COL1A2 in Family 03 was below the theoretical maximum that could be obtained from this family $(+1.55$, Table 1$)$. However, upon sequencing the COL1A2 cDNA from individual II-4, no mutation was found and both alleles were expressed (Zhuang and Spotila, unpublished). Therefore, the COLlA2 gene does not appear to be responsible for the low bone density in this family.

Even though linkage to VDR was not observed, it is theoretically possible that the VDR genotype might be associated with the low bone density trait in these families. However, multiple regression analysis suggested that VDR genotype accounted for only 0.7 and $1.2 \%$ of the variability of spine BMD in men and women, respectively. These results disagree with the association of low BMD at either the spine or the femoral neck with the $B B$ genotype observed by several groups $(21,45,50)$, but the results here support the negative findings of other groups $(22,51,53)$. Several possible explanations can be offered: (1) the contribution of VDR genotype is minor in these families and thus overwhelmed by the other genetic effects; (2) our study population is not random; (3) statistical models used in other investigations cannot be applied to a family group; or (4) the contribution of VDR genotype to $\mathrm{BMD}$ may vary in diverse ethnic groups.

There are a vast number of additional genes that might be considered good candidates affecting low bone density. Thus, we are continuing this analysis by performing a genome-wide screen using highly informative micro-satellite repeats at approximately $10-\mathrm{cM}$ intervals.

\section{ACKNOWLEDGMENTS}

This work was supported by grants from the National Institutes of Health (AR38188 [DJP]), the Shriners Hospital for Crippled Children (\#15958 [MPW]), the National Center for $\mathrm{Hu}$ - man Genome Research (HG00008 [JO]), the March of Dimes/Birth Defects Foundation, and the Lucille P. Markey Charitable Trust. The authors thank Dr. George Lyritis of the University of Athens, Greece, and Dr. Alexander Yantzides of Iatriko Institute, Athens, Greece, for DEXA and laboratory analysis of several subjects in this study.

\section{REFERENCES}

1. Melton III LJ. (1988) Epidemiology of fractures. In: Riggs Jr BL, Melton LJ (eds) Osteoporosis: Etiology, Diagnosis, and Management. Raven Press, New York, pp. 133.

2. Hui SL, Slemenda CW, Johnston PH, Johnston CC. (1989) Baseline measurement of bone mass predicts fracture in white women. Ann. Intern. Med. 111: 355-361.

3. Wasnich RD, Ross PD, Davis JW, Vogel JM. (1989) A comparison of single and multi-site BMC measurements for assessment of spine fracture probability. J. Nucl. Med. 30: $1166-$ 1171.

4. Lloyd T, Rollings N, Andon MB, et al. (1992) Determinants of bone density in young women. I. Relationships among pubertal development, total body bone mass, and total body bone density in premenarchal females. J. Clin. Endocrinol. Metab. 75: 383-386.

5. Gilsanz V, Roe TF, Mora S, Costin G, Goodman WG. (199) Changes in vertebral bone density in black girls and white girls during childhood and puberty. N. Engl. J. Med. 325: 1597-1600.

6. Ott SM. (1990) Editorial: Attainment of peak bone mass. J. Clin. Endocrinol. Metab. 71: 1082A-1082C.

7. Riggs BL, Wahner HW, Melton III JL, Richelson LS, Judd HL, Offord KP. (1986) Rates of bone loss in the appendicular and axial skeletons of women. Evidence of substantial vertebral bone loss before menopause. $J$. Clin. Invest. 77: 1487-1491.

8. Lutz J, Tesar R. (1987) Mother-daughter pairs: spinal and femoral bone densities and dietary intakes. Am. J. Clin. Nutr. 52: 872877.

9. Pocock NA, Eisman JA, Hopper JL, Yeates MG, Sambrook PN, Eberl S. (1987) Genetic determinants of bone mass in adults. A twin study. J. Clin. Invest. 80: 706-710.

10. Kelly PJ, Hopper JL, Macaskill GT, Pockock NA, Sambrook PN, Eisman JA. (1991) Ge- 
netic factors in bone turnover. J. Clin. Endocrinol. Metab. 72: 808-813.

11. Dequeker J, Nijs J, Verstraeten A, Geusens P, Gevers G. (1987) Genetic determinants of bone mineral content at the spine and radius: A twin study. Bone 8: 207-209.

12. Smith DM, Nance WE, Kang KW, Christian JC, Johnston Jr CC. (1973) Genetic factors in determining bone mass. J. Clin. Invest. 52: 2800-2808.

13. Seeman E, Hopper JL, Bach LA, et al. (1989) Reduced bone mass in daughters of women with osteoporosis. N. Engl. J. Med. 320: 554558.

14. Hansen MA, Hassager C, Jensen SB, Christiansen C. (1992) Is heritability a risk factor for postmenopausal osteoporosis? J. Bone Miner. Res. 7: 1037-1043.

15. Krall EA, Dawson-Hughes B. (1989) Heritable and life-style determinants of bone mineral density. J. Bone Miner. Res. 8: 1-9.

16. Pollitzer WS, Anderson JJB. (1989) Ethnic and genetic differences in bone mass: A review with a hereditary vs environmental perspective. Am. J. Clin. Nutr. 50: 1244-1259.

17. Kuivaniemi H, Tromp G, Prockop DJ. (1991) Mutations in collagen genes: causes of rare and some common diseases in humans. FASEB J. 5: 2052-2060.

18. Byers PH, Wallis GA, Willing MC. (1991) Osteogenesis imperfecta: Translation of mutation to phenotype. J. Med. Genet. 28: 433442.

19. Ritchie HH, Hughes MR, Thompson ET, et al. (1989) An ochre mutation in the vitamin D receptor gene causes hereditary 1,25-dihydroxyvitamin $\mathrm{D}_{3}$-resistant rickets in three families. Proc. Natl. Acad. Sci. U. S. A. 86: 97839787.

20. Spotila LD, Colige A, Sereda L, et al. (1994) Mutation analysis of coding sequences for type I procollagen in individuals with low bone density. J. Bone Miner. Res. 9: 923-932.

21. Morrison NA, Qi JC, Tokita A, et al. (1994) Prediction of bone density from vitamin D receptor alleles. Nature 367: 284-287.

22. Hustmyer FG, Peacock M, Hui S, Johnston CJ, Christian J. (1994) Bone mineral density in relation to polymorphism at the vitamin $\mathrm{D}$ receptor gene locus. J. Clin. Invest. 94: 21302134.

23. Wahner HW. (1989) Measurements of bone mass and bone density. Endocrinol. Metab. Clin. North Am. 18: 995-1012.
24. Ott J. (1979) Detection of rare major genes in lipid levels. Hum. Genet. 51: 79-91.

25. Lathrop GM, Lalouel JM, Julier C, Ott J. (1984) Strategies for multilocus linkage analysis in humans. Proc. Natl. Acad. Sci. U. S. A. 81: 3443-3446.24.

26. Riggs BL, Melton LJ. (1986) Involutional osteoporosis. N. Engl. J. Med. 314: 1676-1686.

27. Mazess R, Chestnut $\mathrm{CH}$, McClung M, Genant H. (1992) Enhanced precision with dual-energy x-ray absorptiometry. Calcif. Tissue Int. 51: $14-17$.

28. Weeks DE, Ott J, Lathrop GM. (1990) SLINK: a general simulation program for linkage analysis. Am. J. Hum. Genet. 47: A204.

29. Ott J. (1989) Computer-simulation methods in human linkage analysis. Proc. Natl. Acad. Sci. U. S. A. 86: 4175-4178.

30. Chi DD, Hing AV, Helms C, Steinbrueck T, Mishra SK, Donis-Keller H. (1992) Two chromosome 7 dinucleotide repeat polymorphisms at gene loci epidermal growth factor receptor (EGFR) and proa 2(I) collagen (COL1A2). Hum. Mol. Genet. 1: 135.

31. Pepe G. (1993) A highly polymorphic $(\mathrm{ACT})_{\mathrm{n}}$ VNTR (variable nucleotide of tandem repeats) locus inside intron 12 of COL1A2, one of the two genes involved in dominant osteogenesis imperfecta. Hum. Mutat. 2: 300-305.

32. Cooperative Human Linkage Center (CHLC). (1994) A comprehensive human linkage map with centimorgan density. Science 265: 2049-2073.

33. Dow E, Ferguson-Smith AC, Caplin B, Williamson R. (1992) Dinucleotide repeat polymorphism at the HOX 2B locus. Hum. Mol. Genet. 1: 218.

34. Gyapay G, Morissette J, Vignal A, et al. (1994) The 1993-94 Genethon genetic linkage map. Nat. Genet. 7: 246-339.

35. Wu S, Seino S, Bell GI. (1990) Human collagen, type II, alpha 1, (COL2Al) gene: VNTR polymorphism detected by gene amplification. Nucleic Acids Res. 18: 3102.

36. Berg ES, Olaisen B. (1993) Characterization of the COL2Al VNTR polymorphism. Genomics 16: 350-354.

37. Thode HC, Finch SJ, Mendell NR. (1988) Simulated percentage points for the null distribution of the likelihood ratio test for a mixture of two normals. Biometrics 44: $1195-$ 1201.

38. Labuda M, Fujiwara TM, Ross MV, et al. 
(1992) Two hereditary defects related to vitamin D metabolism map to the same region of human chromosome 12q13-14. J. Bone Miner. Res. 7: 1447-1453.

39. NIH/CEPH Collaborative Mapping Group. (1992) A comprehensive genetic linkage map of the human genome. Science 258: 6786.

40. Easton DF, Bishop DT, Ford D, Crockford GP, the Breast Cancer Linkage Consortium. (1993) Genetic linkage analysis in familial breast and ovarian cancer: results from 214 families. Am. J. Hum. Genet. 52: 678-701.

41. Peltomäki P, Aaltonen LA, Sistonen $P$, et al. (1993) Genetic mapping of a locus predisposing to human colorectal cancer. Science 260: $810-811$.

42. Davies JL, Kawaguchi Y, Bennett ST, et al. (1994) A genome-wide search for human type 1 diabetes susceptibility genes. Nature 371: $130-136$.

43. Jeunemaitre $X$, Soubrier F, Kotelevtsev YV, et al. (1992) Molecular basis of human hypertension: role of angiotensinogen. Cell 71: 169-180.

44. Weissenbach JG, Gyapay C, Dib C, et al. (1992) A second-generation linkage map of the human genome. Nature 359: 794-801.

45. Ferrari S, Rizzoli R, Chevalley T, Slosman D, Eisman JA, Bonjour J-P. (1995) Vitamin-Dreceptor-gene polymorphisms and change in lumbar-spine bone mineral density. Lancet 345: 423-424.

46. Yamagata Z, Miyamura T, Iijima S, Asaka A, Kato J, Koizumi K. (1994) Vitamin D receptor gene polymorphism and bone mineral

Contributed by D. J. Prockop on March 11, 1996. density in healthy Japanese women. Lancet 344: 1027.

47. Krall EA, Parry P, Lichter JB, DawsonHughes B. (1995) Vitamin D receptor alleles and rates of bone loss: Influences of years since menopause and calcium intake. J. Bone Miner. Res. 10: 978-984.

48. Fleet JC, Harris SS, Wood RJ, DawsonHughes B. (1995) The BsmI vitamin D receptor restriction fragment length polymorphism (BB) predicts low bone density in premenopausal black and white women. $J$. Bone Miner. Res. 10: 985-990.

49. Riggs BL, Nguyen TV, Melton LJ, et al. (1995) The contribution of vitamin D receptor gene alleles to the determination of bone mineral density in normal and osteoporotic women. J. Bone Miner. Res. 10: 991-996.

50. Spector TD, Keen RW, Arden NK, et al. (1995) Vitamin D receptor gene (VDR) alleles and bone density in postmenopausal women: A UK twin study. Br. Med. J. 310: 1357-1360.

51. Melhus H, Kindmark A, Amer $S$, et al. (1994) Vitamin D receptor genotypes in osteoporosis. Lancet 344: 949-950.

52. Gallagher JC, Goldgar D, Kinyamu H, Fannon P. (1994) Vitamin D receptor genotypes in type I osteoporosis. J. Bone Miner. Res. 9(Suppl 1): 90.

53. Looney J, Fischer $M$, Yoon $H$, et al. (1995) Lack of high prevalence of the $\mathrm{BB}$ vitamin $\mathrm{D}$ receptor genotype in severely osteoporotic women. J. Clin. Endocrinol. Metab. 80: 21582162 . 